\title{
Fuzzy based power control of a hybrid active wind generator for distributed power generation
}

\author{
Prof. D. Shobha Rani ${ }^{1}$, Tellapati Anuradha Devi ${ }^{2}$, K.Hanumantha Rao ${ }^{3}$ \\ 1, 2, 3(Department of EEE, Vardhaman College of Engineering (Autonomous), JNTU Hyderabad, India)
}

\begin{abstract}
A dc-coupled wind/hydrogen/super capacitor hybrid power system using fuzzy logic is studied in this paper. The purpose of the control system is to coordinate these different sources, particularly their power exchange, in order to make controllable the generated power. As a result, an active wind generator can be built to provide some ancillary services to the grid. The control system should be adapted to integrate the power management strategies. Two power management strategies are presented and compared experimentally. We found that the "source-following" strategy has better performances on the grid power regulation than the "grid-following" strategy.
\end{abstract}

Keywords - Distributed power, energy management, hybrid power system (HPS), power control, wind generator (WG), Fuzzy logic system.

\section{INTRODUCTION}

Renewable energy sources (RES) and distributed generations (DGs) have attracted special attention all over the world in order to reach the following two goals:

1) The security of energy supply by reducing the dependence on imported fossil fuels;

2) The reduction of the emission of greenhouse gases (e.g., $\mathrm{CO} 2$ ) from the burning of fossil fuels.

Other than their relatively low efficiency and high cost, the controllability of the electrical production is the main drawback of renewable energy generators, like wind turbines and photovoltaic panels, because of the uncontrollable meteorological conditions. In consequence, their connection into the utility network can lead to grid instability or even failure if they are not properly controlled. Moreover, the standards for interconnecting these systems to the utility become more and more critical and require the DG systems to provide certain services, like frequency and voltage regulations of the local grid. Wind power is considered in this paper. Wind energy is the world's fastest growing energy source, expanding globally at a rate of $25 \%-35 \%$ annually over the last decade (Fig. 1).

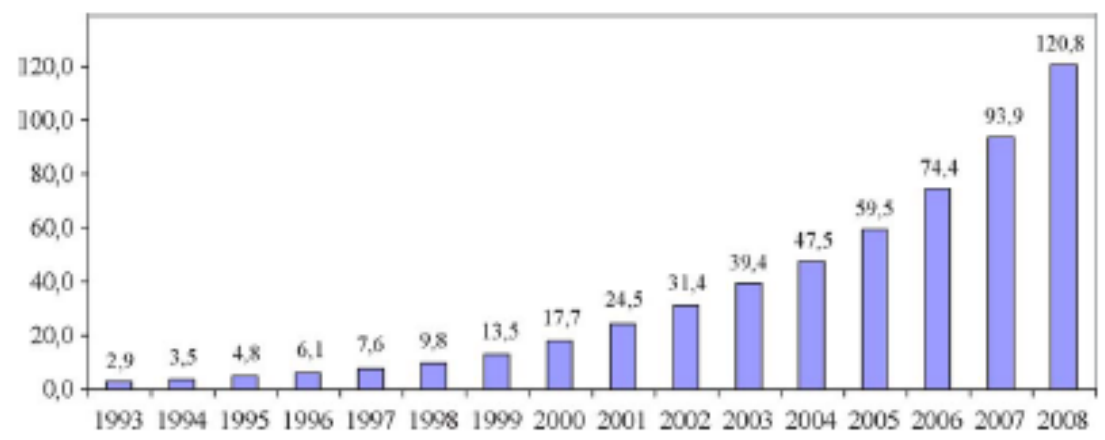

Fig. 1. Total wind power (in giga watts) installed in the world since 1993.

However, classical wind energy conversion systems work like passive generators. Because of the intermittent and fluctuant wind speed, they cannot offer any ancillary services to the electrical system in a microgrid application, where stable active- and reactive-power requirements should be attributed to the generators. As solutions, hybrid power systems (HPS) are proposed to overcome these problems with the following two innovative improvements.

\section{A. Structure of HPS:}

\section{Fuzzy Based Hps Control System}

In this paper, we use a dc-coupled structure in order to decouple the grid voltages and frequencies from other sources. All sources are connected to a main dc bus before being connected to the grid through a main inverter (Fig. 2). Each source is electrically connected with a power-electronic converter in order to get possibilities for power control actions. Moreover, this HPS structure and its global control system can also be used for other combinations of sources. 


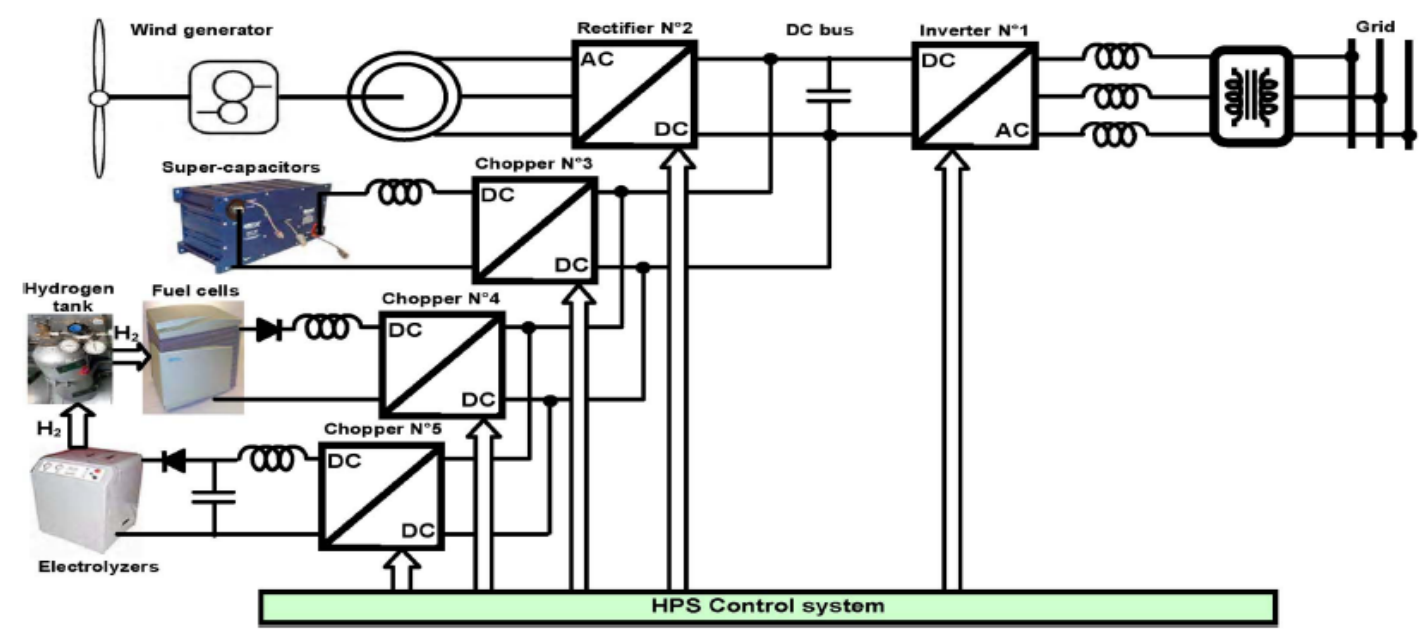

Fig.2. Structure of the studied wind/hydrogen/SC HPS.

\section{B. Structure of Control System:}

Power converters introduce some control inputs for power conversion. In this case, the structure of the control system can be divided into different levels (Fig. 3).

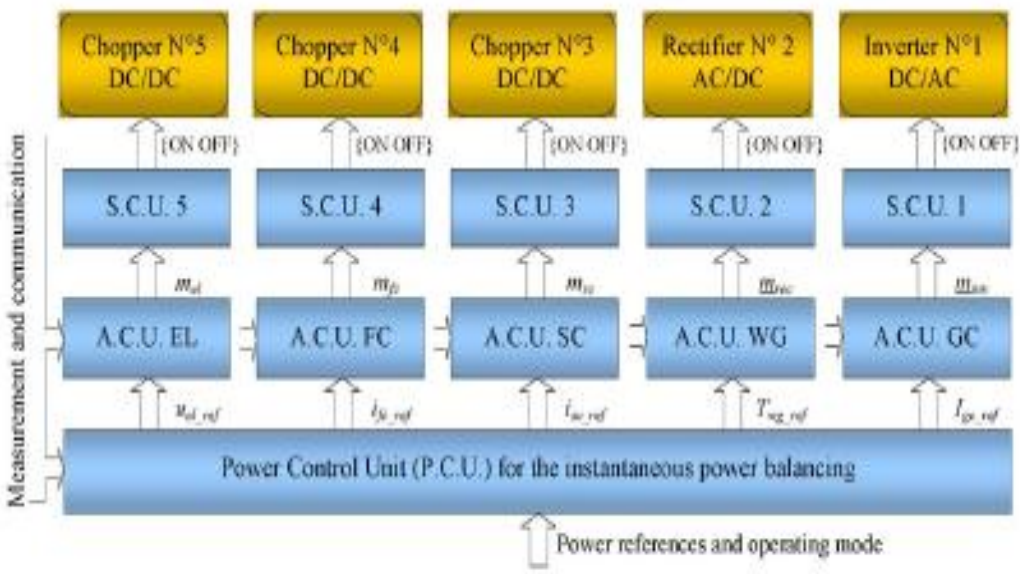

Fig.3.Hierarchical control structure of the HPS.

The switching control unit (SCU) is designed for each power converter. In an SCU, the drivers with optocouplers generate the transistor's ON/OFF signals from the ideal states of the switching function $\{0,1\}$, and the modulation technique (e.g., pulse width modulation) determines the switching functions from the modulation functions (m).

The automatic control unit (ACU) is designed for each energy source and its power conversion system. In an ACU, the control algorithms calculate the modulation functions (m) for each power converter through the regulation of some physical quantities according to their reference values.

The power control unit (PCU) is designed to perform the instantaneous power balancing of the entire HPS in order to satisfy the grid requirements. These requirements are real- and reactive-power references, which are obtained from the secondary control center and from references of droop controllers. In a PCU, some powerbalancing algorithms are implemented to coordinate the power flows of different energy sources. The different power-balancing algorithms correspond to a number of possible operating modes of the HPS and can be gathered.

The purpose of this paper is to present the power-balancing strategies in the PCU. In order to focus on the power-balancing strategies of the HPS, the control schemes of the power conversion systems through different power converters will not be detailed in this paper. However, some explanations of the ACUs are given in the following paragraphs in order to make the controllable variables of the power conversion systems appear.

\section{ACU:}

The control schemes in the ACUs are shown in Fig. 4 with block diagrams.

1) The EL power conversion system is controlled by setting the terminal voltage $\left(\mathrm{u}_{\mathrm{el}}\right)$ equal to a prescribed reference $\left(\mathrm{u}_{\mathrm{e} \_ \text {ref }}\right)$ through the dc chopper $\mathrm{N} \circ 5$. The EL stack is considered as an equivalent current source $\left(\mathrm{i}_{\mathrm{el}}\right)$. 
2) The FC power conversion system is controlled with a reference of the FC current ( $\left.i_{f_{c} \_r e f}\right)$ through the $d c$ chopper $\mathrm{N} \circ 4$. The $\mathrm{FC}$ stack is considered as an equivalent voltage source $\left(\mathrm{u}_{\mathrm{fc}}\right)$.

3) The $\mathbf{S C}$ power conversion system is controlled with a current reference $\left(\mathrm{i}_{\mathrm{sc} \_ \text {ref }}\right)$ through the dc chopper $\mathrm{N} \circ 3$. The $\mathrm{SC}$ bank is considered as an equivalent voltage source $\left(\mathrm{u}_{\mathrm{sc}}\right)$.

4) The wind energy conversion system is controlled with a reference of the gear torque ( $T_{\text {gear_ref }}$ by the threephase rectifier $\mathrm{N} \circ 2$.

5) The grid connection system consists of a dc-bus capacitor and a grid power conversion system. The grid power conversion system is controlled with line-current references ( $\left.i_{l_{\_} \text {ref }}\right)$ by the three-phase inverter $\mathrm{N} \circ 1$, because the grid transformer is considered as an equivalent voltage source $\left(\mathrm{u}_{\text {grid }}\right)$.

The dc-bus voltage is described as

$$
C_{\mathrm{dc}}=\frac{d u_{\mathrm{dc}}}{d t}=i_{\mathrm{dc}} .
$$

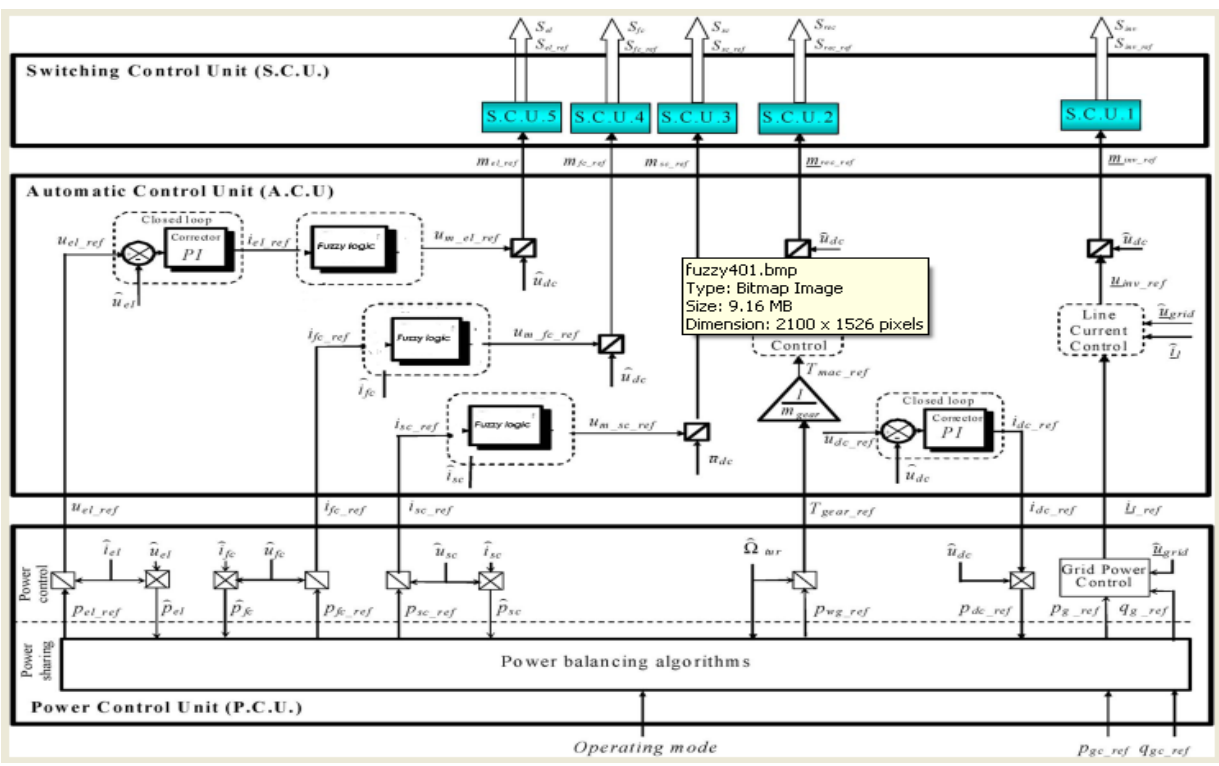

Fig.4. Modeling and control of the HPS by the Energetic Macroscopic Representation.

In order to control the dc-bus voltage, a voltage controller must be used. The output of the voltage controller is a current reference $i_{\text {dc_ref }}($ Fig. 4).

\section{A. Layout of PCU:}

\section{Power Control Units}

The power modeling of the HPS can be divided into two levels: the power calculation level and the power flow level (Fig. 5). Thus, the PCU is also divided into two levels: the power control level and the power sharing level.

The PCU enables one to calculate references for the ACU from power references. The power sharing level coordinates the power flow exchanges among the different energy sources with different power-balancing strategies. They are presented here in detail with the help of the Multilevel Representation (Fig. 5), which was developed by Peng Li in 2008. 


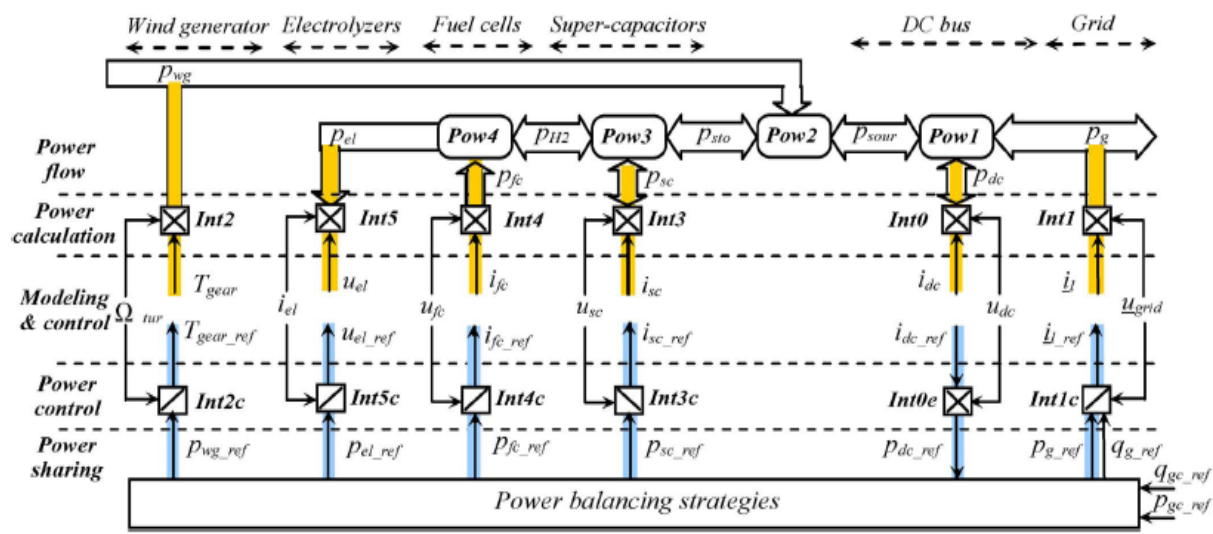

Fig. 5. Multilevel representation of the power modeling and control of the HPS.

\section{B. Power Control Level:}

The power exchanges with various sources are controlled only via the related five references (uel_ref, ifc_ref, isc_ref, Tgear_ref, and $i_{1 \_ \text {ref }}$ in Fig. 5). Therefore, the expressions of the powers should be deduced in order to obtain these power references (Table I). Only the sources' powers and the exchanged power with the dc-bus capacitor are taken into account here. For the energy storage systems, the powers are calculated by multiplying the measured currents and the measured voltages (Int3, Int4, and Int5 in Table I). The references of the controllable variables are obtained by dividing the power reference with the measured current or the measured voltages (Int3c, Int4c, and Int5c in Table I).

\section{Table I}

\section{Summary Of Equations For Power Calculation}

\begin{tabular}{|c|c|c|}
\hline & Power calculation & Power control \\
\hline$D C$ & $\operatorname{IntO}: p_{d c}=u_{d c} i_{d c}$ & Intoe: $p_{d c_{-} r e f}=u_{d c} i_{d k_{-} r e f}$ \\
\hline$G C$ & Intl: $\left\{\begin{array}{l}p_{g}=u_{13} i_{1}+u_{23} i_{2} \\
q_{g}=\sqrt{3}\left\langle u_{13} i_{1}-u_{23} i_{2}\right\rangle\end{array} \quad\right.$ Int $/ c:$ & $\left\{\begin{array}{l}i_{l_{1} \text { reff }}=\frac{\left(2 u_{13}-u_{23}\right) p_{g_{-} r e f}+\sqrt{3} u_{23} q_{z_{-} \text {ref }}}{2 u_{13}^{2}-2 u_{13} u_{23}+2 u_{23}^{2}} \\
i_{z_{2} \text { ref }}=\frac{\left(2 u_{23}-u_{13}\right) p_{g_{-} r f f}-\sqrt{3} u_{13} q_{g_{-} r e f}}{2 u_{13}^{2}-2 u_{13} u_{23}+2 u_{23}^{2}}\end{array}\right.$ \\
\hline$W G$ & $\operatorname{lnt} 2: p_{\mathrm{ug}}=\Omega_{\text {gear }} T_{\text {gear }}$ & $\operatorname{lnt} 2 c: T_{\text {gear__ref }}=p_{\text {wog_nef }} / \Omega_{\text {gear }}$ \\
\hline$S C$ & Int3: $p_{s c}=u_{s c} i_{s c}$ & Int $3 c: i_{s c \_n f}=p_{s c_{-} r e f} / u_{s c}$ \\
\hline$F C$ & $\operatorname{Int}: p_{x}=i_{x} u x$ & 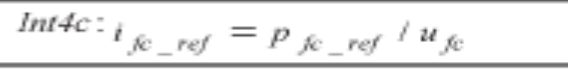 \\
\hline$E L$ & Int5: $p_{e l}=i_{e l} u_{e l}$ & $I n t 5 c: u_{e t_{-} r e f}=p_{f E_{-} r e f} / i_{f N}$ \\
\hline
\end{tabular}

For the wind energy conversion system, a maximal-power-point- tracking (MPPT) strategy is used to extract the maximum power of the available wind energy according to a nonlinear characteristic in function of the speed. It receives the measured rotational speed $\left(\Omega_{\text {tur }}\right)$ and sets a desired power reference ( $\left.p_{\mathrm{wg} \_r e f}\right)$ (Int 2 and Int2c in Table I).

The output of the dc-bus voltage control loop is the current reference (idc_ref ) of the dc-bus capacitor, and its product with the measured dc-bus voltage gives the power reference

$\left(\mathrm{p}_{\mathrm{dc} \_ \text {ref }}\right)$ for the dc-bus voltage regulation (Int0e). The powers, which are exchanged with the grid, can be calculated with the "two-wattmeter" method (Int1 and Int1c in Table I). In order to focus on the power exchanges with the different sources around the dc bus, the instantaneously exchanged power with the choke, the losses in the filters, and the losses in the power converters are neglected.

\section{Power Sharing Level:}

The power sharing level is used to implement the power balancing strategies in order to coordinate the various sources in the HPS (Fig. 5). It plays a very important role in the control system, because the power exchanges lead directly to the stability of the HPS and impact the dc-bus voltage $\left(\mathrm{u}_{\mathrm{dc}}\right)$. 


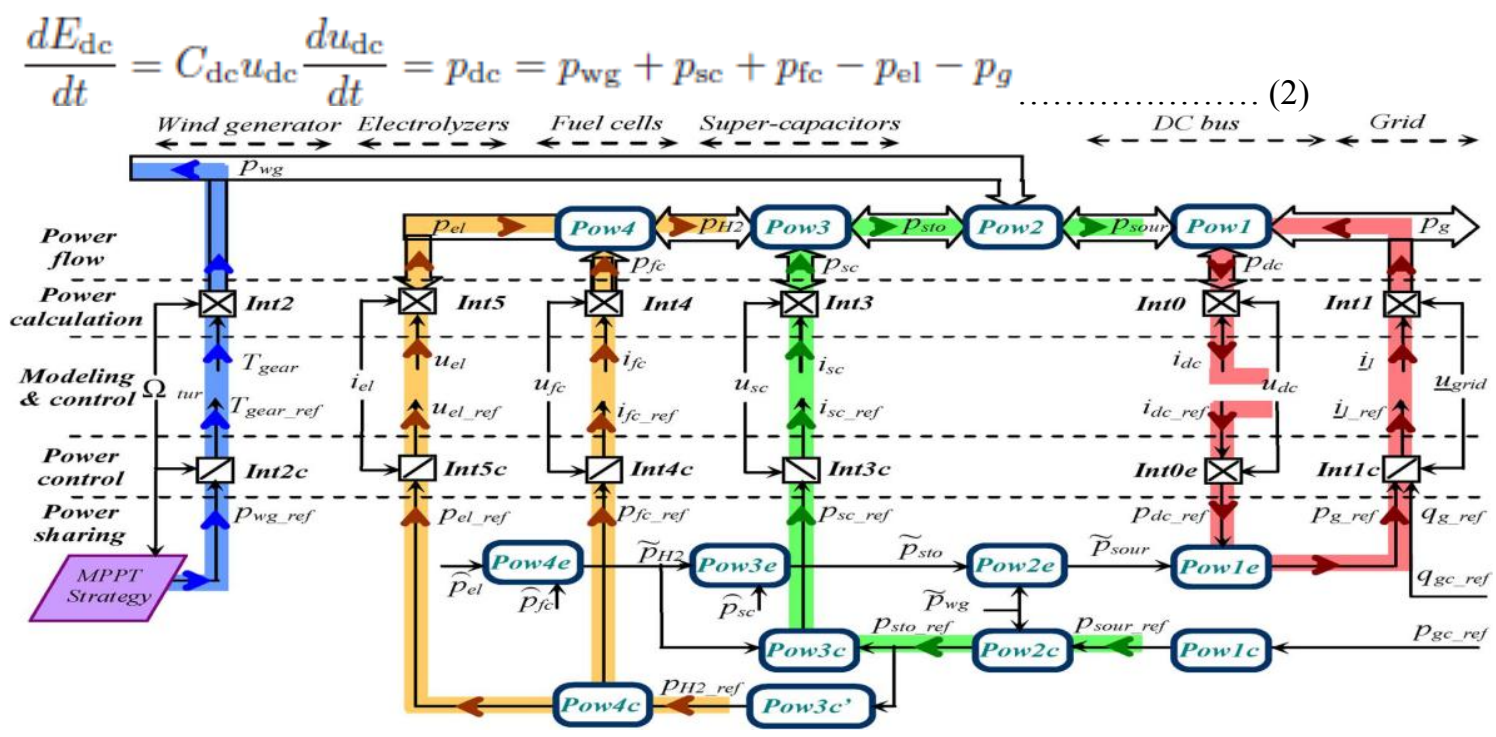

Fig:6. Multilevel representation of the Grid-following strategy

With

$\mathrm{E}_{\mathrm{dc}}$ stored energy in the dc-bus capacitor;

$\mathrm{p}_{\mathrm{dc}}$ resulted power into the dc-bus capacitor;

$\mathrm{p}_{\mathrm{wg}}$ generated power from the WG;

$\mathrm{p}_{\mathrm{fc}}$ generated power from the $\mathrm{FC}$;

$\mathrm{p}_{\mathrm{sc}}$ exchanged power with the SC;

$\mathrm{p}_{\mathrm{el}}$ consumed power by the EL;

$\mathrm{p}_{\mathrm{g}}$ delivered power into the grid from the dc bus.

According to the power exchange, the power flows inside this HPS are modeled with four equations.

$$
\begin{array}{cl}
\text { Pow 1 : } & p_{g}=p_{\mathrm{sour}}-p_{\mathrm{dc}} \ldots \\
\text { Pow 2: } & p_{\mathrm{sour}}=p_{\mathrm{sto}}+p_{\mathrm{wg}} \\
\text { Pow 3 : } & p_{\mathrm{sto}}=p_{\mathrm{H} 2}+p_{\mathrm{sc}} \\
\text { Pow 4: } & p_{\mathrm{H} 2}=p_{\mathrm{fc}}-p_{\mathrm{el}} \ldots .
\end{array}
$$

With

$\mathrm{p}_{\text {sour }}$ "source" total power arriving at the dc bus;

$\mathrm{p}_{\text {sto }}$ "storage" total power arriving at the dc bus;

$\mathrm{p}_{\mathrm{H} 2}$ "hydrogen" total power arriving at the dc bus.

In this wind/hydrogen/SC HPS, five power-electronic converters are used to regulate the power transfer with each source. According to a chosen power flow, the following two power balancing strategies can be implemented.

1) The grid-following strategy uses the line-current loop to regulate the dc-bus voltage.

2) The source-following strategy uses the line-current loop to control the grid active power, and the dc-bus voltage is regulated with the WG and storage units.

\section{Power-Balancing Strategies}

\section{A. Grid-Following Strategy:}

With the grid-following strategy, the dc-bus voltage is regulated by adjusting the exchanged power with the grid, while the WG works in MPPT strategies [27]. In Fig. 6, the dc-bus voltage control is shown by a closed loop ( $\mathrm{p}_{\mathrm{dc} \_ \text {ref }} \rightarrow \mathrm{p}_{\mathrm{g} \_ \text {ref }} \rightarrow \mathrm{p}_{\mathrm{g}} \rightarrow \mathrm{p}_{\mathrm{dc}}$ ). Thus, the required power for the dc-bus voltage regulation (pdc_ref) is used to estimate the grid power reference

( $\left.\mathrm{p}_{\mathrm{g} \_\mathrm{ref}}\right)$.

$$
\text { Pow1e: } \quad p_{g \_ \text {ref }}=\tilde{p}_{\text {sour }}-\tilde{p}_{\text {dc_ref }}
$$

The source total power (psour) is a disturbance and should also be taken into account with the estimated wind power and the sensed total storage power

Pow2e: $\quad \tilde{p}_{\text {sour }}=\tilde{p}_{\mathrm{wg}}+\tilde{p}_{\text {sto }}$ 
The energy storage systems help the wind energy conversion system satisfy the power references, which are asked by the microgrid operator

$$
\begin{array}{cc}
\text { Pow3e: } & \tilde{p}_{\mathrm{sto}}=\widehat{p}_{\mathrm{sc}}+\widehat{p}_{\mathrm{H} 2} \\
\text { Pow4e: } & \tilde{p}_{\mathrm{H} 2}=\widehat{p}_{\mathrm{fc}}-\widehat{p}_{\mathrm{el}}
\end{array}
$$

In steady state, the dc-bus voltage is regulated, and the averaged power exchange with the dc-bus capacitor can be considered as zero in (3). Hence, in steady state, the grid power (pg) is equal to the total power from the sources (psour). If the microgrid system operator sets a power requirement ( $\left.\mathrm{p}_{\mathrm{gc} \_ \text {ref }}\right)$, it must be equal to the sources' power reference $\left(\mathrm{p}_{\text {sour_ref }}\right)$, as shown in Fig. 6.

Pow1c: $\quad p_{\text {sour_ref }}=p_{g_{\text {ref }}}=p_{\text {gc_ref }}$.

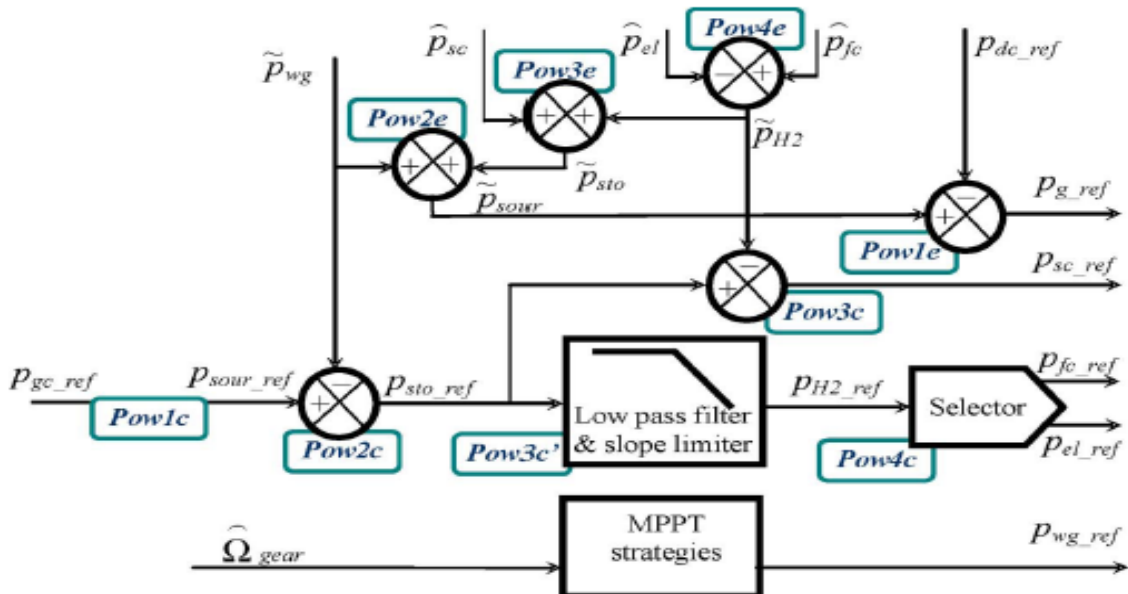

Fig.7.Block diagram of the grid-following strategy.

In order to help the wind energy conversion system respect the active-power requirement, the energy storage systems should be coordinated to supply or absorb the difference between this power requirement (pgc_ref ) and the fluctuant wind power (pwg), as shown in Fig. 6

$$
\text { Pow } 2 c: \quad p_{\text {sto_ref }}=p_{\text {sour_ref }}=\tilde{p}_{\text {wg }} \text {. }
$$

Among the energy storage systems, the FCs and the ELs are the main energy exchangers because a large quantity of hydrogen can be stored for enough energy availability. For efficiency reasons, the FC and the EL should not work at the same time. The activation of the FC or the activation of the EL depends on the sign of the reference $\left(\mathrm{p}_{\mathrm{H} 2 \_ \text {ref }}\right)$. Thus, a selector assigns the power reference $\left(\mathrm{p}_{\mathrm{H} 2 \_ \text {ref }}\right)$ to the FC ( $\left.\mathrm{p}_{\mathrm{fc} \_ \text {ref }}\right)$ or to the EL $\left(\mathrm{p}_{\text {el__ref }}\right)$ according to the sign of $\mathrm{pH} 2$ ref (Fig. 6)

$$
\begin{aligned}
& \text { Pow4C: } \\
& \begin{cases}\text { if: } p_{\mathrm{H} 2 \_ \text {ref }}>\varepsilon, & p_{\mathrm{fc} \_ \text {ref }}=p_{\mathrm{H} 2 \_ \text {ref }} ; p_{\text {el_ref }}=0 \\
\text { if: }\left|p_{\mathrm{H} 2 \_ \text {ref }}\right| \leq \varepsilon, & p_{\mathrm{fc} \_ \text {ref }}=0 ; p_{\text {el_ref }}=0 \\
\text { if: } p_{\mathrm{H} 2 \_ \text {ref }}<-\varepsilon, & p_{\mathrm{fc} \_ \text {ref }}=0 ; p_{\text {el_ref }}=\left|p_{\mathrm{H} 2 \_ \text {ref }}\right| .\end{cases}
\end{aligned}
$$

However, the power reference ( $\mathrm{p}_{\text {sto_ref }}$ ) is a fast-varying quantity due to the fluctuant wind power $(\mathrm{pwg})$ and the varying grid power (pg). In order to avoid the fast-chattering problem when it is close to zero, it should be slowed down. Moreover, the FCs and the ELs have relatively slow power dynamics, and fast-varying power references are not welcome for their operating lifetime. Therefore, a low-pass filter (LPF) with a slope limiter should be added (Fig. 6)

$$
\text { Pow3 } c^{\prime}: \quad p_{\text {H2_ref }}=\frac{1}{1+\tau s}\left(p_{\text {sto_ref }}\right)
$$

where $\tau$ is the time constant of the LPF and should be set large enough by taking into account the power dynamics of the FCs and the ELs, as well as the size of the SCs.

The SCs are not made for a long-term energy backup unit because they have limited energy storage capacities due to their low energy density. However, they have very fast power dynamics and can supply fastvarying powers and power peaks. They can be used as an auxiliary power system of the FCs and ELs to fill the power gaps during their transients 


$$
\text { Pow3c: } \quad p_{\mathrm{sc} \text { ref }}=p_{\text {sto_ref }}-\bar{p}_{\mathrm{H} 2}=p_{\text {sto_ref }}-\bar{p}_{\mathrm{fc}}+\bar{p}_{\mathrm{el}}
$$

The block diagram of the grid-following strategy for the active WG is shown in Fig. 7.

\section{B. Source-Following Strategy:}

The total power $\left(\mathrm{p}_{\text {sour }}\right.$ ) from the energy storage and the WG can also be used to provide the necessary dc power (pdc) for the dc-bus voltage regulation (Fig. 8). In this case, the necessary total power reference $\left(\mathrm{p}_{\text {sour_ref }}\right)$ must be calculated by taking into account the required power for the dc-bus voltage regulation (pdc_ref ) and the measured grid power (pg) as disturbance input by using the inverse equation of Pow1 (Fig. 8)

$$
\text { Powle: } \quad p_{\text {sour_ref }}=p_{\text {de_ref }}+\hat{p}_{g} \text {. }
$$

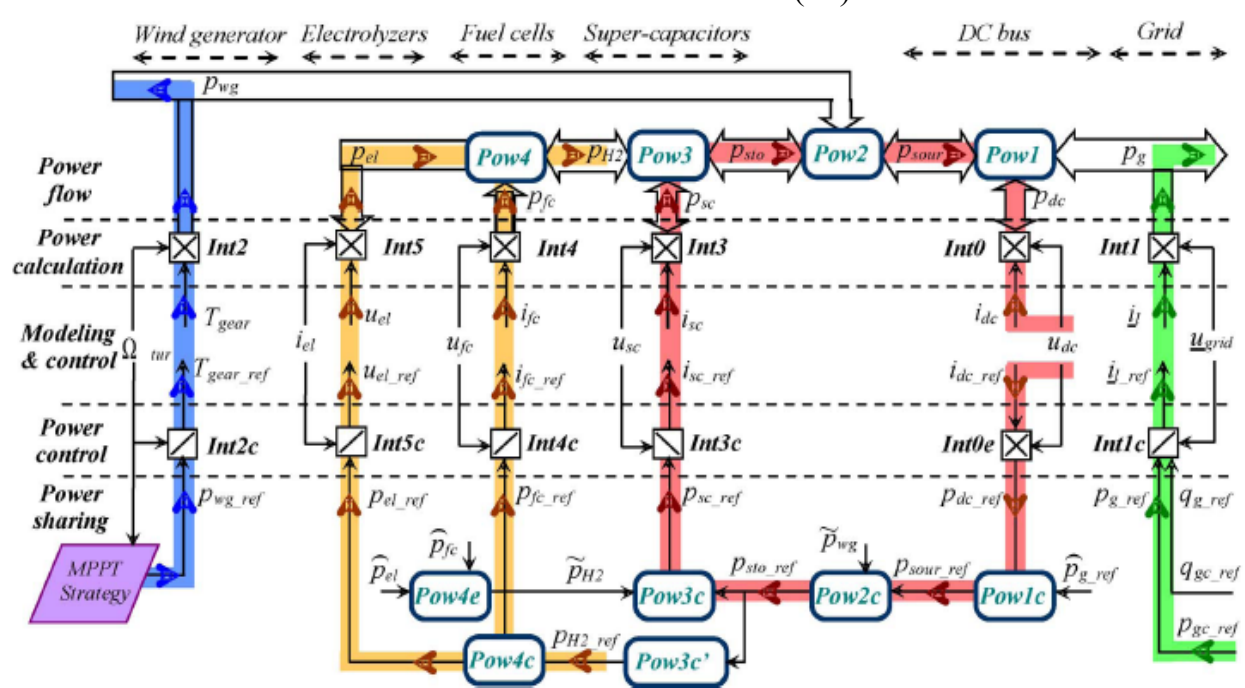

Fig.8. Multilevel representation of the source-following strategy

Then, the total power reference of the storage systems is deduced by taking into account the fluctuant wind power with the inverse equation of Pow2 (Fig. 8)

$$
\text { Pow2c: } \quad p_{\text {sto_ref }}=p_{\text {sour_ref }}-\tilde{p}_{\text {wg }} \text {. }
$$

This power reference is shared among the FCs, the ELs, and the SCs in the same way as explained earlier (Pow2c, Pow3c, Pow4c, and Pow 3c). In addition, now, the grid power reference $\left(\mathrm{p}_{\mathrm{g}}\right.$ ref $)$ is free to be used for the grid power control. The microgrid system operator can directly set the power requirements $\left(\mathrm{p}_{\mathrm{gc} \_ \text {ref }}\right.$ and $\mathrm{q}_{\mathrm{gc} \_ \text {reet }}$ ) for the grid connection system $\left(\mathrm{p}_{\mathrm{g} \_ \text {ref }}=\mathrm{p}_{\mathrm{gc} \_ \text {ref }}\right)$. Therefore, the HPS can directly supply the required powers for providing the ancillary services to the microgrid, like the regulations of the grid voltage and frequency.

The block diagram of the grid-following strategy for the active WG is shown in Fig. 9.

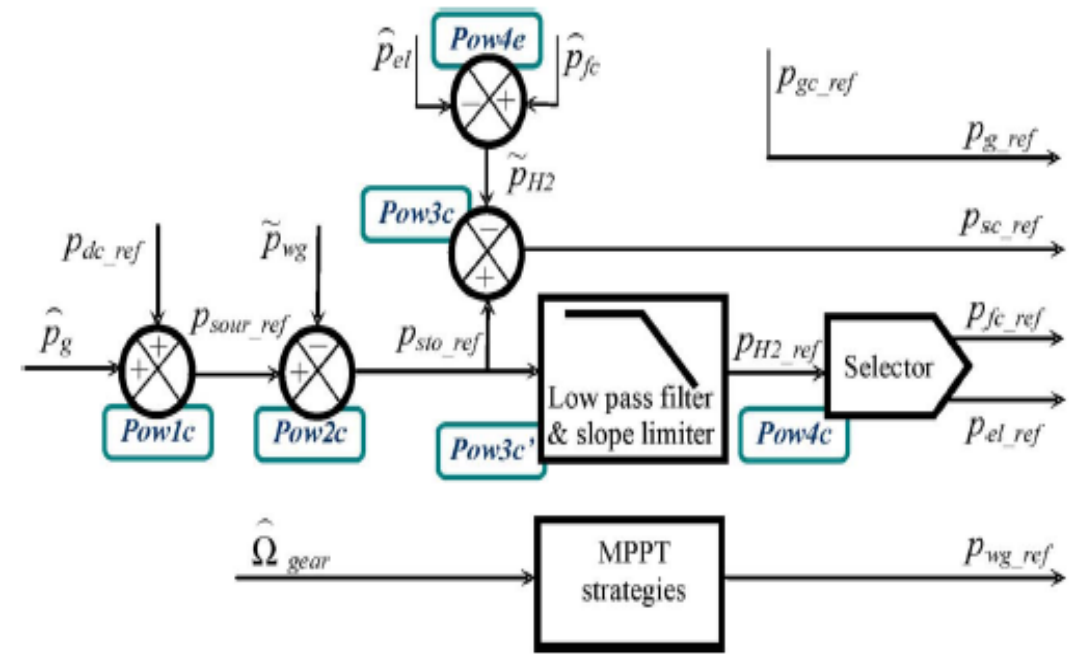


Fig.9. Block diagram of the source-following strategy.

\section{A. Experimental Platform Assessment}

\section{Experimental Tests}

An experimental platform of the HPS has been built to test the different power-balancing strategies. Hardware-In-the-Loop (HIL) emulations of a part of a power system enable a fast experimental validation test before implementation with the real process. Some parts of the emulator process are simulated in real time in a controller board and are then interfaced in hardware with the real devices. Such a HIL simulation has been intensively used and enables one to check the availability and reliability of the hybrid active WG (storage component sizing, power-electronic interface, and operation control). The FC and EL emulators are used to provide the same electrical behavior as the real FC stack and the EL stack [28]. Models of the FCs and the EL have been previously validated through comparisons with obtained experimental results and simulated results from models. They are implemented in a digital control board (DSpace 1102) and calculated voltages

And currents are generated by using power-electronic converters. Three "Boostcap SC" modules (160 $\mathrm{F}$ and $48 \mathrm{~V}$ ) are connected in series (Table II). Therefore, the equivalent capacitor of the SC bank is about $53 \mathrm{~F}$, and the maximal voltage is about $144 \mathrm{~V}$. All sources are connected to the dc bus through different power converters (Fig. 10). The dc bus is connected to the grid through a three-phase inverter, three line filters, and a grid transformer. Moreover, the HPS is controlled by a digital control board (DSpace 1103). The wind power emulator is used to provide the predefined reduced wind power profile pwg $(1.2 \mathrm{~kW})$. The sizing of the FC and EL stacks is adapted by using the modeling parameters of Table II in the HIL simulation in order to be interfaced in the experimental test bench. Two power-balancing strategies are tested and compared, respectively.

With this experimental test bench, it is possible to apply our proposed hierarchical control system for the active generator and to test it with the developed power-balancing strategies.

\section{B. Power Profile of Different Sources}

Two tests are performed experimentally for both strategies,respectively. The same fluctuant wind power profile is used during $150 \mathrm{~s}$ (Fig. 11). The active-power requirement from the microgrid is assumed to be pgc_ref $=600 \mathrm{~W}$. Similar power profiles are obtained for the energy storage systems (Fig. 11). When the generated wind power is more than $600 \mathrm{~W}$, the EL is activated to absorb the power difference, but when the generated wind power is less than $600 \mathrm{~W}$, the FC is activated to compensate the power difference. Since the power dynamics of the FCs and the EL are limited by an LPF with a 5-s time constant, they are not able to filter the fast fluctuations of the wind power. Therefore, the SCs supply or absorb the power difference.

\section{Grid Following Strategy}

In the grid-following strategy, the dc-bus voltage is well regulated around $400 \mathrm{~V}$ by the grid power conversion system (Fig. 12). The energy storage systems help the WG supply the microgrid power requirement (psour $=$ pgc_ref $=600 \mathrm{~W})$. Because of the different power losses in the filters and power converters, the grid active power is slightly less than the microgrid's requirement $\left(\mathrm{pg}<\mathrm{pgc} \_\right.$ref $\left.=600 \mathrm{~W}\right)$.

\section{Source-Following Strategy}

In the grid-following strategy, the energy storage systems are controlled to supply or absorb the necessary powers in order to maintain the dc-bus voltage (around $400 \mathrm{~V}$ ) against the fluctuant wind power (Fig. 13). The grid active power is also regulated and is equal to the microgrid's requirement, because the line-current control loop regulates directly the grid powers $\left(\mathrm{pg}=\mathrm{pgc} \_\right.$ref $=600 \mathrm{~W}$ ). Therefore, the sourcefollowing strategy has better performances on the grid power regulation than the grid-following strategy, and it can provide ancillary services according to the microgrid's requirements.

\section{E. Comparison and Discussion}

Thanks to the help of energy storage systems, the dc-bus voltage and the grid powers can be well regulated with both power-balancing strategies, while the WG extracts the maximum available wind power. By comparing the two power-balancing strategies with their experimental test results (Figs. 12 and 13), we see that the grid active power is better regulated in the "grid-following" strategy than in the "source-following" strategy. In the grid-following strategy, the grid power varies continuously because the linecurrent control loop regulates the dc-bus voltage and the grid power is adjusted all the time. In the source-following strategy, the dc-bus voltage is regulated by the SCs, and the grid power can be directly used to supply the same power as required by the microgrid system operator. Thus, if the active generator is required to provide the necessary powers to participate in the microgrid management, the source-following strategy is preferred for more precisely controlling the grid powers. 


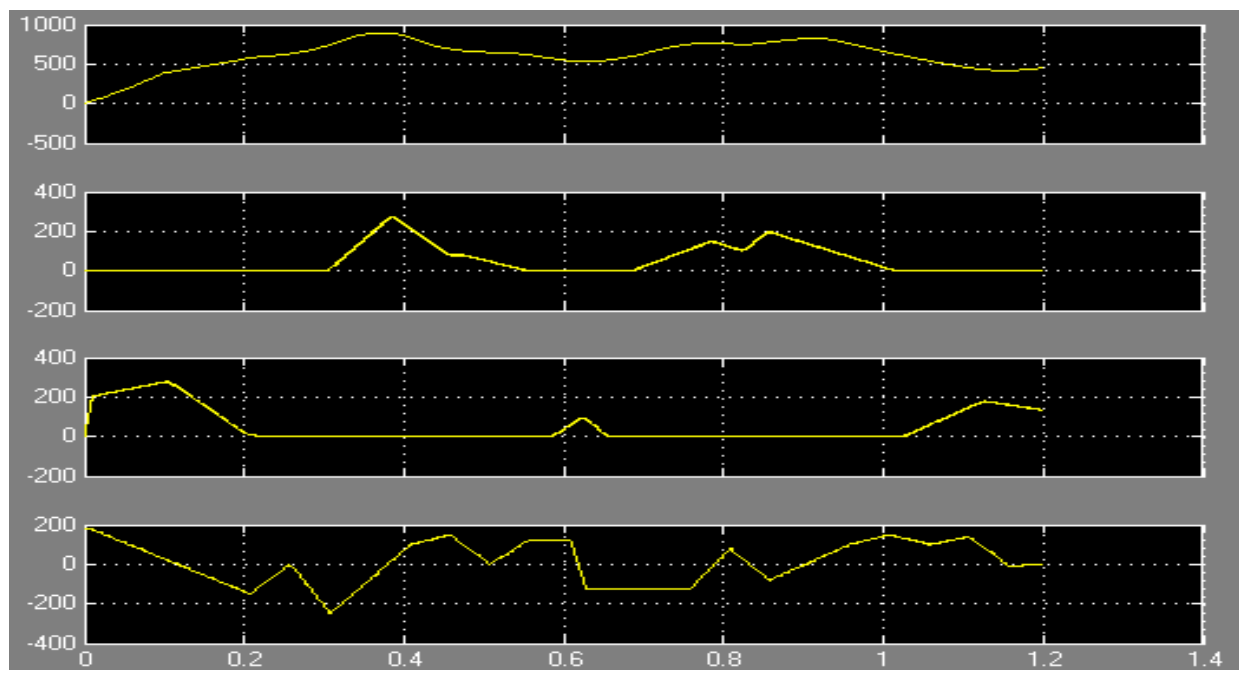

Fig.11. Power profiles of the different sources.

Fuzzy ruled based grid following strategy:

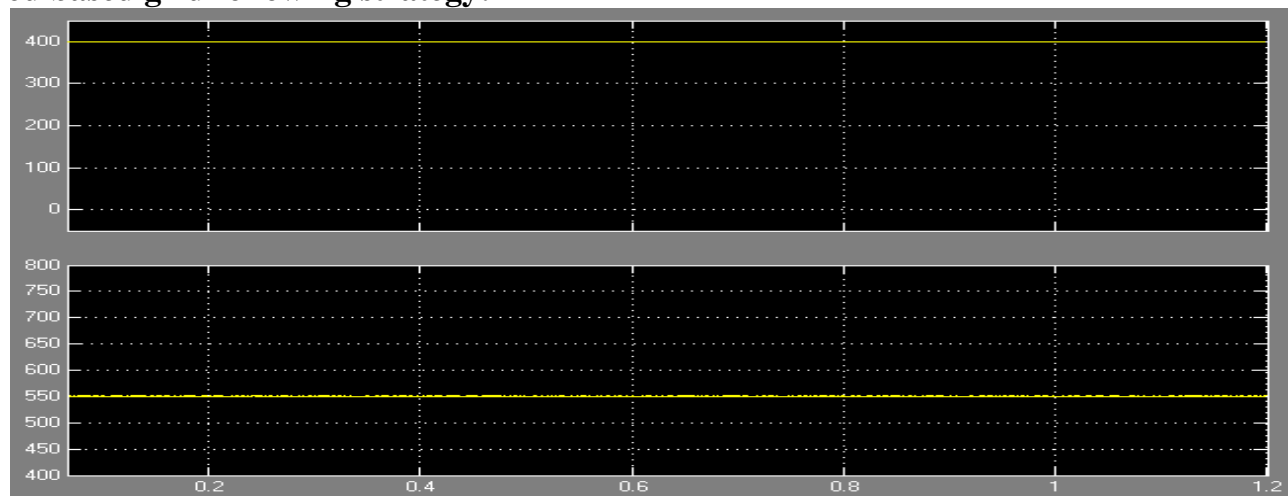

Fig. 12.Grid-following strategy test results.

Fuzzy ruled based source following strategy:

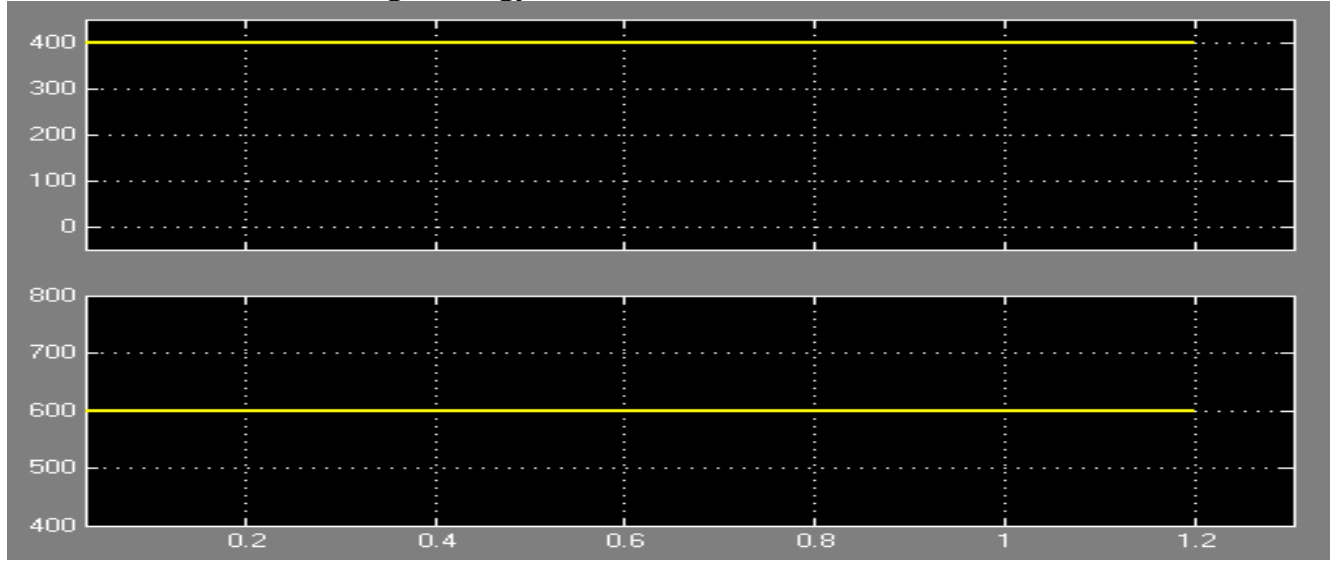

Fig. 13.Source-following strategy test results.

\section{Conclusion}

In this paper, a dc-coupled fuzzy based HPS has been studied with the three kinds of energy sources: 1) a WG as a renewable energy generation system; 2) SCs as a fast-dynamic energy storage system; and 3) FCs with ELs and hydrogen tank as a longterm energy storage system. The structure of the control system is divided into three levels: 1) SCU; 2) ACU; and 3) PCU. Two power-balancing strategies have been presented and compared for the PCU: the grid-following strategy and the source following strategy. For both of them, the dc-bus voltage and the grid power can be well regulated. The experimental tests have shown that the source-following strategy has better performance on the grid power regulation than the grid-following strategy by using the fuzzy logic system. 


\section{REFERENCES}

[1] W. Li, G. Joos, and J. Belanger, "Real-time simulation of a wind turbine generator coupled with a battery supercapacitor energy storage system,"IEEE Trans. Ind. Electron., vol. 57, no. 4, pp. 1137-1145, Apr. 2010. [Online]. Available: http://www.eurobserver.org/

[3] G. Delille and B. Francois, "A review of some technical and economic features of energy storage technologies for distribution systems integration,” Ecol. Eng. Environ. Prot., vol. 1, pp. 40-49, 2009.

[4] C. Abbey and G. Joos, "Supercapacitor energy storage for wind energy applications," IEEE Trans. Ind. Electron., vol. 43, no. 3, pp. 769-776, May 2007

[5] G. Taljan, M. Fowler, C. Cañizares, and G. Verbi č, "Hydrogen storage for mixed wind-nuclear power plants in the context of a Hydrogen Economy," Hydrogen Energy, vol. 33, no. 17, pp. 4463-4475, Sep. 2008.

[6] M. Little, M. Thomson, and D. Infield, "Electrical integration of renewable energy into stand-alone power supplies incorporating hydrogen storage," Hydrogen Energy, vol. 32, no. 10, pp. 1582-1588, Jul. 2007.

[7] T. Zhou, D. Lu, H. Fakham, and B. Francois, "Power flow control in different time scales for a wind/hydrogen/super-capacitors based active hybrid power system," in Proc. EPE-PEMC, Poznan, Poland, Sep. 2008, pp. 2205-2210.

[8] F. Baalbergen, P. Bauer, and J. A. Ferreira, "Energy storage and power management for typical 4Q-load," IEEE Trans. Ind. Electron., vol. 56, no. 5, pp. 1485-1498, May 2009.

[9] D. Ipsakis, S. Voutetakis, P. Seferlis, F. Stergiopoulos, and C. Elmasides, "Power management strategies for a stand-alone power system using renewable energy sources and hydrogen storage," Hydro. Energy, vol. 4, no. 16, pp. 7081-7095, Aug. 2009.

[10] U.S. Department of Energy, Energy Efficiency and Renewable Energy, Wind \& Hydropower Technologies Program, Wind Energy Research Area. [Online]. Available: http://www.eere.energy.gov

[11] M. Lebbal, T. Zhou, B. Francois, and S. Lecoeuche, "Dynamically electrical modelling of electrolyzer and hydrogen production regulation," in Proc. Int. Hydrogen Energy Congr. Exhib., Istanbul, Turkey, Jul. 2007.

[12] R. M. Dell and D. A. J. Rand, "Energy storage-A key technology for global energy sustainability,” Power Sources, vol. 100, no. $1 / 2$, pp. 2-17, Nov. 2001.

[13] B. D. Shakyaa, L. Ayea, and P. Musgraveb, "Technical feasibility and financial analysis of hybrid wind-photovoltaic system with hydrogen storage for Cooma," Hydro. Energy, vol. 30, no. 1, pp. 9-20, Jan. 2005.

[14] O. Gabriel, C. Saudemont, B. Robyns, and M. M. Radulescu, "Control and performance evaluation of a flywheel energy-storage system associatedto a variable-speed wind generator,” IEEE Trans. Ind. Electron, vol. 53, no. 4, pp. 1074-1085, Aug. 2006.

[15] R. Cardenas et al., "Control strategies for power smoothing using a flywheel driven by a sensorless vector-controlled induction machine operating in a wide speed range," IEEE Trans. Ind. Electron., vol. 51, no. 3, pp. 603-614, Jun. 2004.

[16] P. Li, P. Degobert, B. Robyns, and B. Francois, "Participation in the frequency regulation control of a resilient microgrid for a distribution network,” Int. J. Integr. Energy Syst., vol. 1, no. 1, Jan. 2009.

[17] J. M. Guerrero, J. C. Vasquez, J. Matas, M. Castilla, and L. G. de Vicuna, "Control strategy for flexible microgrid based on parallel line-interactive UPS systems,” IEEE Trans. Ind. Electron., vol. 56, no. 3, pp. 726-736, Feb. 2009.

[18] C. Sudipta, D. W. Manoja, and M. G. Simoes, "Distributed intelligent energy management system for a single-phase high-frequency AC microgrid," IEEE Trans. Ind. Electron., vol. 54, no. 1, pp. 97-109, Feb. 2007.

[19] D. M. Vilathgamuwa, C. L. Poh, and Y. Li, "Protection of microgrids during utility voltage sags," IEEE Trans. Ind. Electron., vol. 53, no. 5, pp. 1427-1436, Oct. 2006.

[20] M. Prodanovic and T. C. Green, "High-quality power generation through distributed control of a power parkmicrogrid," IEEE Trans. Ind. Electron., vol. 53, no. 5, pp. 1427-1436, Oct. 2006.

[21] T. Iqbal, B. Francois, and D. Hissel, "Dynamic modeling of a fuel cell and wind turbine DC-linked power system," in Proc. 8th Int. Conf. Model. Simul. ELECTRIMACS, Hammamet, Tunisia, 2004, [CD-ROM].

[22] T. Zhou and B. Francois, "Modeling and control design of hydrogen production process for an active wind hybrid power system," Int. J. Hydrogen Energy, vol. 34, no. 1, pp. 21-30, Jan. 2009.

[23] O. C. Onar, M. Uzunoglu, and M. S. Alam, "Dynamic modeling design and simulation of a wind/fuel cell/ultra-capacitor-based hybrid power generation system,” Power Sources, vol. 161, no. 1, pp. 707-722, Oct. 2006.

[24] J. M. Guerrero, J. Matas, G. V. Luis, M. Castilla, and J. Miret, "Decentralized control for parallel operation of distributed generation inverters using resistive output impedance,” IEEE Trans. Ind. Electron., vol. 54, no. 2, pp. 994-1004, Apr. 2007.

[25] J. C. Vasquez, J. M. Guerrero, A. Luna, P. Rodriguez, and R. Teodorescu, "Adaptive droop control applied to voltage-source inverters operating in grid-connected and islanded modes,” IEEE Trans. Ind. Electron., vol. 56, no. 10, pp. 4048-4096, Oct. 2009.

[26] P. Li, B. Francois, P. Degobert, and B. Robyns, "Multi-level representation for control design of a super capacitor storage system for a microgrid connected application," in Proc. ICREPQ, Santander, Spain, Mar. 12, 2008.

[27] T. Zhou, P. Li, and B. François, "Power management strategies of a DC-coupled hybrid power system for microgrid operations," in Proc. $13^{\text {th }}$ Int. Eur. Power Electron. Conf. Exhib. EPE, Barcelona, Spain, Sep. 2009, pp. 1-10, [CD-ROM].

[28] T. Zhou and B. Francois, "Real-time emulation of a hydrogen production process for assessment of an active wind energy conversion system,” IEEE Trans. on Ind. Electron., vol. 56, no. 3, pp. 737-746, Mar. 2009 